\title{
ANNONA CONTRERASII (ANNONACEAE), ESPECIE NUEVA DEL ESTADO DE GUERRERO, MÉXICO
}

\author{
JaIme JimÉNEZ-RamíreZ ${ }^{1,3}$ Y José CARMEN Soto-NÚÑEZ ${ }^{2}$ \\ ${ }^{1}$ Universidad Nacional Autónoma de México, Facultad de Ciencias, \\ Departamento de Biología Comparada, Ciudad Universitaria, \\ Circuito Exterior, 04510 México, D.F., México. \\ ${ }^{2}$ Universidad Nacional Autónoma de México, Instituto de Biología, \\ Departamento de Botánica, Ciudad Universitaria, Circuito Exterior, \\ 04510 México, D.F., México. \\ ${ }^{3}$ Autor para la correspondencia: jjimenez_ramirez@yahoo.com
}

\section{RESUMEN}

Se describe e ilustra a Annona contrerasii de la sección Helogenia Saff. (Annonaceae), una especie nueva del estado de Guerrero, México. El nuevo taxon es parecido a Annona crotonifolia Mart. de Sudamérica, pero difiere de ésta por representar arbustos a árboles de mayor tamaño y tener hojas más angostas con un número mayor de venas secundarias, peciolos más cortos, tricomas simples, sépalos trulados y de menor tamaño, pétalos interiores rómbicos, estambres de menor tamaño, pistilos glabros y frutos de tamaño mayor.

Palabras clave: Annona, Annonaceae, Guerrero, Helogenia, México.

\begin{abstract}
Annona contrerasii of section Helogenia Saff. (Annonaceae), a new species from the state of Guerrero, Mexico, is described and illustrated. The new taxon is similar to Annona crotonifolia Mart. from South America, from which if differs by representing larger shrubs to trees, and having narrower leaves with a larger number of secondary veins, shorter petioles, simple trichomes, trulate and smaller sepals, rhombic inner petals, smaller stamens, glabrous pistils and larger fruits.
\end{abstract}

Key words: Annona, Annonaceae, Guerrero, Helogenia, Mexico. 
El género Annona L. (Annonaceae) se distribuye en los trópicos de América y África. Cuenta con alrededor de 200 especies e incluye a los géneros Raimondia Saff. y Rollinia A. St.-Hil., según Rainer (2007) y Chatrou et al. (2012). De acuerdo con Andrés Agustín y Segura Ledesma (2014), tiene 18 especies registradas en la República Mexicana, distribuidas en las zonas de clima cálido. Algunas son cultivadas por su uso comestible como la chirimoya, la ilama y la guanábana, entre otras. Los estados con mayor riqueza son Veracruz (12 especies), Chiapas y Yucatán (6) y Jalisco y Quintana Roo (5). Para Guerrero únicamente se señalan dos especies, de las que destaca $A$. diversifolia Saff. (ilama) por el extendido uso de su fruto comestible.

En el estudio de la flora arbórea del estado de Guerrero se recolectaron algunos ejemplares que se ubican en el género Annona L., de acuerdo con la clave genérica mundial de Couvreur et al. (2012), por conjuntar las siguientes características: indumento con tricomas simples, hojas dísticas, vena principal impresa en el haz, flores trímeras, supra-axilares, pétalos carnosos, androceo sin estaminodios, frutos sincárpicos y carpelos monospermos. Asimismo, en la clave de Salvador-Esparza (2010), citada por Andrés Agustín y Andrés Hernández (2012) para determinar a los géneros mexicanos de Annonaceae, se separa fácilmente a Annona L. y Rollinia A. St.-Hil. del resto de los taxones por tener fruto sincárpico, de manera que las plantas halladas pertenecen indudablemente al género Annona L.

Los ejemplares encontrados pertenecen a la sección Helogenia Saff. (Safford, 1914; Fries, 1931), caracterizada por tener flores con 6 pétalos libres y desiguales; los 3 externos son mucho más largos y anchos que los 3 interiores. Dicho carácter floral no se encuentra en ninguna de las especies de Annona L. hasta ahora conocidas para México. Solamente se observa en las de la sección Helogenia Saff., cuya distribución se consideraba restringida a Sudamérica, por lo que el hallazgo de plantas mexicanas de tal sección resulta particularmente notable. Esta sección es monofilética según la hipótesis filogenética del género Annona L. de Rainer (2013), lo cual corrobora a la circunscripción propuesta por Safford (1914).

Las hojas de las plantas colectadas presentan cierto parecido con las del género Salix L. y son muy diferentes de las del resto de las especies de la sección Helogenia Saff. Los representantes de esta última tienen hojas con limbos anchos y base redondeada, salvo A. crotonifolia Mart., caracterizada por hojas lanceoladas, estrechamente elípticas o rara vez elípticas, con base aguda (Fries, 1931). Por ello se describe a continuación una especie nueva y se presenta el Cuadro 1, donde se muestran las diferencias respecto a la última especie mencionada. 
Annona contrerasii J. Jiménez Ram. \& J. C. Soto, sp. nov. Fig. 1.

A. crotonifolia Mart. affinis, sed arbores vel frutices. (1.5-)3-5 m sunt, foliis angustioribus, trichomatibus simplicibus, magis venis lateralibus, petiolis brevioribus, sepalis trullatis et brevioribus, petalis internis rhombicis, staminibus brevioribus, pistillis glabris et fructibus majoribus.

Árboles o arbustos de (1.5-)3-5 m de alto, ramillas jóvenes cubiertas densamente por tricomas pluricelulares, adpresos y ferrugíneos, ramas glabrescentes o glabras. Hojas de 6.6-14.5 cm de largo; láminas de 6-14.4 x (0.7-)0.9-1.8 cm, lanceoladas; venas laterales con (6-)10-14(-17) pares, que se curvan ligeramente hacia el ápice de la hoja, ápice agudo a acuminado, base largamente atenuada, glabras o glabrescentes, con tricomas pluricelulares adpresos blancos o ferrugíneos; pecíolo de 0.6-4 mm de largo. Inflorescencias internodales, con flores solitarias o en pares, pedúnculo de 4.2-5.5 $\mathrm{mm}$ de largo, pedicelo de 5.6-10 $\mathrm{mm}$ de largo, bráctea de 3.6$3.8 \mathrm{~mm}$ de largo, ovado-triangular, acuminada; bracteola de 1.6-1.7 $\mathrm{mm}$ de largo, anchamente ovada, acuminada. Flores con sépalos de 3.8-4.2 x 4.2-4.5 mm, trulados, ápice apiculado, esparcidamente pilosos, glabrescentes, margen piloso; pétalos libres, los externos 3, verdes o verde-amarillentos, valvados, ovados, de 18.7-22 x 11.1-11.5 mm, ápice acuminado, superficie abaxial ligeramente pilosa, superficie adaxial glabra, los pétalos internos 3, de 11.6-15 x 3.25-5.5 mm, blancos o amarillos, rómbicos, ápice agudo, base decurrente, glabros; receptáculo cortamente cilíndrico; estambres numerosos (más de 100), de 1.85-2.5 mm de largo, apéndice apical prismático con la parte superior cubierta de papilas blanco-amarillentas; carpelos 59-72, pistilos de 1-1.4 mm de largo, glabros. Frutos inmaduros cónicos, de 2.7-3.4 x 2.3-2.6 $\mathrm{cm}$, areolas ligeramente muricadas. Semilla madura desconocida.

Tipo: MÉXICO. Guerrero, municipio La Unión de Isidoro Montes de Oca, rancho El Cóbano aproximadamente a $2 \mathrm{~km}$ al $\mathrm{N}$ del poblado de La Unión, selva

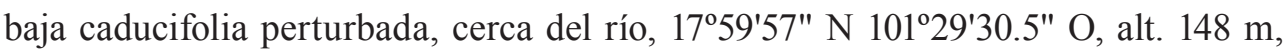
20 junio 2012 (flor y fruto), J. C. Soto Núñez 20171 (holotipo: FCME; isotipos: IEB, MEXU).

Distribución y ecología. Solamente se conoce del estado de Guerrero, México, en los bordes arenosos de los ríos de La Unión y Balsas, asociada a vegetación riparia con selva baja caducifolia o a selva baja caducifolia perturbada, a 50-178 m de altitud. 


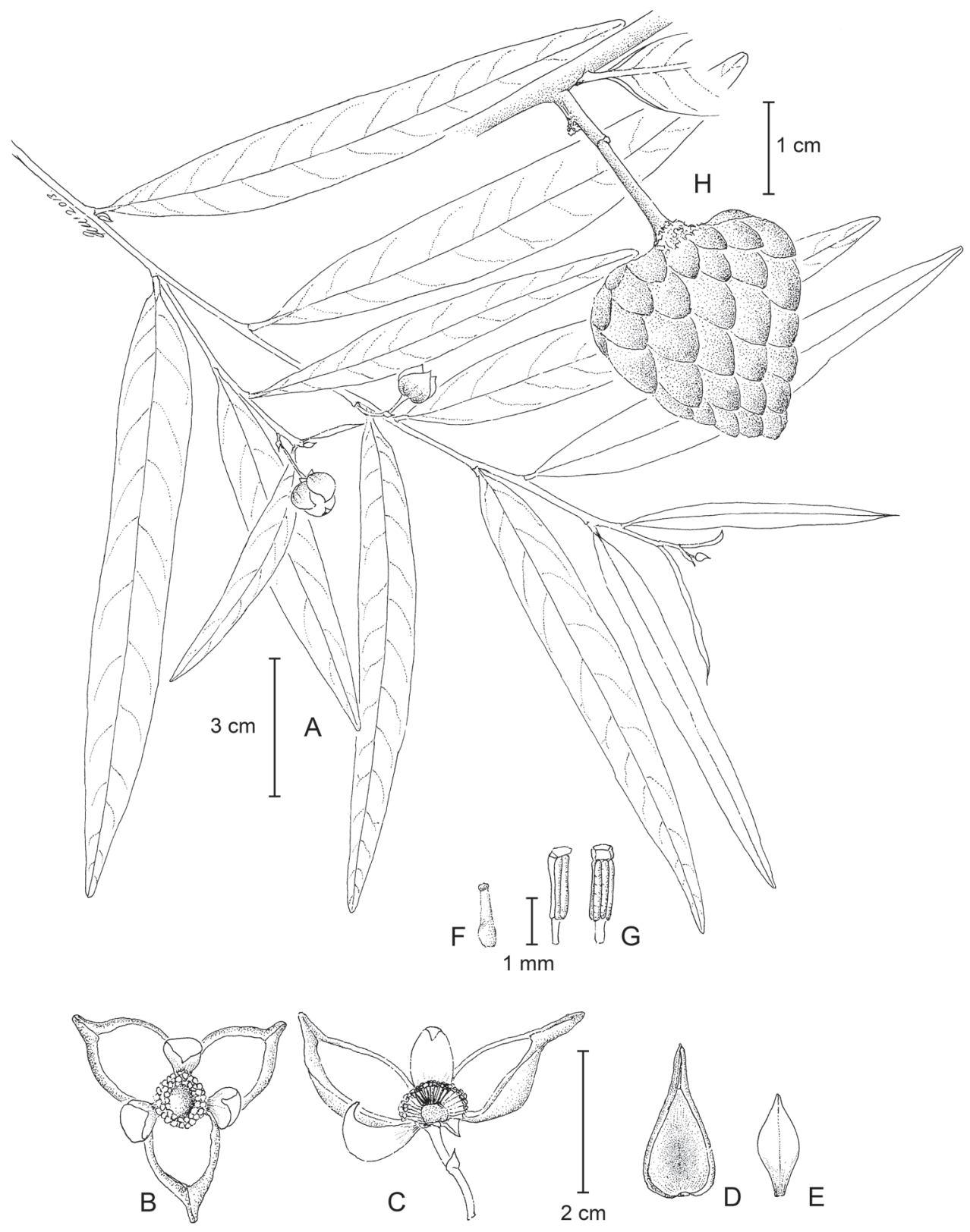

Fig. 1. Annona contrerasii J. Jiménez Ram. \& J. C. Soto. A. rama con hojas y flores; B. flor, vista superior; C. flor vista lateral; D. pétalo externo; E. pétalo interno; F. carpelo; G. estambres, vista frontal y lateral; H. fruto. (A-H dibujado de J. C. Soto 20171, FCME). Ilustración de Ramiro Cruz Durán. 
Fenología. Florece de febrero a junio, fructifica en junio.

Nombre común. Anonillo, el fruto es comestible.

Etimología. El epíteto específico hace referencia a José Luis Contreras Jiménez, botánico mexicano que ha hecho valiosas contribuciones al conocimiento de la flora de Guerrero, y quien realizó la primera colecta de la especie nueva.

Ejemplares examinados. MÉXICO. Guerrero: municipio La Unión de Isidoro Montes de Oca, aproximadamente a $2.5 \mathrm{~km}$ al $\mathrm{N}$ del poblado de La Unión, por el camino al Corral Falso, vegetación riparia asociada a selva baja caducifolia pertur-

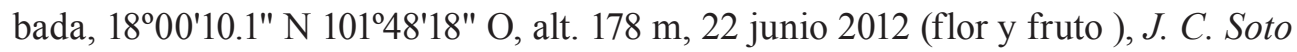
Núñez 20243 (FCME, MEXU); margen izquierda del río Unión, junto al poblado del mismo nombre, en la carretera rumbo a Las Pilas, terrenos a la orilla del río con pendiente abrupta de aluvión y arenosos, alt. $50 \mathrm{~m}, 3$ febrero 1993 (botón floral), $E$. Guizar Nolazco 3038 y L. Pimentel Bibriesca (MEXU); municipio Coahuayutla de José María Izazaga, La Garita, $1 \mathrm{~km}$ al sur del Infiernillo, margen del río Balsas, suelo aluvial (arenoso), alt. 60 m, 14 junio 1988 (flor abierta), J. L. Contreras Jiménez 2382 (FCME).

Annona contrerasii difiere de A. crotonifolia Mart. por el tamaño de sus individuos, el ancho de las hojas, el largo de los pecíolos, el tipo de tricomas, el número de venas laterales de las láminas foliares, el tamaño y forma de los sépalos, el ancho de los pétalos exteriores, la forma de los pétalos interiores, el tamaño de los estambres y frutos, además de la ausencia de indumento en los carpelos, como puede verse en el Cuadro 1.

\section{AGRADECIMIENTOS}

A tres revisores anónimos y al comité editorial de Acta Botanica Mexicana quienes contribuyeron a mejorar substancialmente al manuscrito original; a Ramiro Cruz Durán, la ilustración de la especie; a Susana Valencia Ávalos y Rosa María Fonseca Juárez, la revisión crítica del manuscrito; a Martha Martínez Gordillo, la diagnosis latina; a José Antonio Hernández, la digitalización de la ilustración de la especie. 
Cuadro 1. Comparación entre Annona contrerasii y A. crotonoides (las características de la última especie son tomadas de Fries, 1931).

\begin{tabular}{|c|c|c|}
\hline & A. contrerasii & A. crotonoides \\
\hline Hábito & árbol o arbusto & arbusto \\
\hline tamaño & $(1.5-) 3-5 \mathrm{~m}$ & $1-1.5 \mathrm{~m}$ \\
\hline \multicolumn{3}{|l|}{ Hojas } \\
\hline forma & lanceolada & $\begin{array}{l}\text { lanceolada a estrechamente } \\
\text { elíptica, rara vez elíptica }\end{array}$ \\
\hline ancho & $(0.7-) 0.9-1.8 \mathrm{~cm}$ & $1-5.5 \mathrm{~cm}$ \\
\hline venas laterales & $(6-) 10-14(-17)$ & $7-10$ \\
\hline pecíolo & $0.6-4 \mathrm{~mm}$ & $5-6 \mathrm{~mm}$ \\
\hline tricomas & simples & estrellados \\
\hline \multicolumn{3}{|l|}{ Sépalos } \\
\hline forma & trulada & ovado-triangular \\
\hline largo & $3.8-4.2 \mathrm{~mm}$ & $7-10 \mathrm{~mm}$ \\
\hline indumento & glabrescente & $\begin{array}{l}\text { denso, no deja ver la } \\
\text { epidermis }\end{array}$ \\
\hline \multicolumn{3}{|l|}{ Pétalos exteriores } \\
\hline ancho & $11-15 \mathrm{~mm}$ & $18-20 \mathrm{~mm}$ \\
\hline \multicolumn{3}{|l|}{ Pétalos interiores } \\
\hline forma & rómbica & lanceolada \\
\hline \multicolumn{3}{|l|}{ Estambres } \\
\hline largo & $1.85-2.5 \mathrm{~mm}$ & $3 \mathrm{~mm}$ \\
\hline \multicolumn{3}{|l|}{ Carpelos } \\
\hline indumento & glabro & densamente piloso \\
\hline \multicolumn{3}{|l|}{ Frutos } \\
\hline forma & cónica (inmaduros) & ovoide \\
\hline tamaño & $2.7-3.4 \times 2.3-2.6 \mathrm{~cm}$ & $2.5 \times 2 \mathrm{~cm}$ \\
\hline Distribución geográfica conocida & México (Guerrero) & Brasil y Paraguay \\
\hline
\end{tabular}

\section{LITERATURA CITADA}

Andrés Agustín, J. y L. Andrés Hernández. 2012. Biología, diversidad, conservación y uso sostenible de los recursos genéticos de Annonaceae de México. Universidad Autónoma de Chapingo. Texcoco, México. 146 pp.

Andrés Agustín, J. y S. D. Segura Ledesma. 2014. Conservación y uso de los recursos genéticos de Annonaceae en México. Rev. Bras. Frutic. 36(1): 118-124. 
Chatrou, L. W., M. D. Pirie, R. H. J. Erkens, T. L. P. Couvreur, K. M. Neubig, J. R. Abbott, J. B. Mols, J. W. Maas, R. M. K. Saunders y M. W. Chase. 2012. A new subfamilial and tribal classification of the pantropical flowering plant family Annonaceae informed by molecular phylogenetics. Bot. J. Linn. Soc. 169(1): 5-40.

Couvreur, T. L. P., P. J. M. Maas, S. Meinke, D. M. Johnson y P. J. A. Keesler. 2012. Keys to the genera of Annonaceae. Bot. J. Linn. Soc. 169(1): 74-83.

Fries, R. E.1931. Revision der Arten einiger Annonaceen-Gattungen.II. Annona. Acta Horti Berg. 10(2): 197-315.

Rainer, H. 2007. Monographic studies in the genus Annona L. (Annonaceae): inclusion of the genus Rollinia A. St. Hil. Ann. Naturhist. Mus. Wien 108B: 191-205.

Rainer, H. 2013. Taxonomy of Annonanaceae. Annona and Rollinia. V Congreso de Annonaceae, Botucatu, Brasil. http://es.slideshare.net/HeimoRainer/taxonomyannona-rollinia-vcongresssoannonaceae-20130820

Safford, W. E. 1914. Classification of the genus Annona, with descriptions of new and imperfectly known species. Contr. U.S. Natl. Herb. 18(1): 11-12. 